\title{
KAJIAN DESAIN AWAL SISTEM TERMAL SATELIT ORBIT RENDAH
}

\author{
Ahmad Fauzi $^{\text {a) }}$, Poki Agung Budiantoro ${ }^{\text {b) }}$ \\ Pusat Teknologi Satelit-LAPAN, Jl. Cagak Satelit Km.04 Rancabungur, Bogor, West Java - Indonesia \\ Email: a)fauzi7557@gmail.com, b)pokiagung@gmail.com
}

\begin{abstract}
Abstrak
Sub sistem termal satelit merupakan bagian dari engineering system satelit yang mempunyai peranan penting dalam suatu rancang bangun satelit. Sub sistem termal mempunyai tujuan untuk menjaga semua komponen satelit dengan batasan-batasan suhu yang diijinkan. Batasan suhu dari semua sub sistem satelit perlu diperhatikan agar misi operasional satelit bisa tercapai. Pada makalah ini dibahas tentang besaran suhu yang terjadi pada satelit orbit rendah yang di rancang bangun. Metode yang digunakan adalah sistem keseimbangan energi yang terjadi pada struktur utama satelit (MPS, main parts of the satellite) dengan pendekatan persamaan matematis. Dari metode yang digunakan diperoleh hasil desain awal termal, suhu panas maksimum dan suhu dingin minimum yang terjadi pada struktur utama satelit (MPS) adalah sebesar $22.82^{\circ} \mathrm{C}$ dan $-69.86^{\circ} \mathrm{C}$.
\end{abstract}

Kata-kata kunci: thermal, satelit, suhu, energi.

\begin{abstract}
Satellite thermal systems are part of satellite engineering systems that have an important role in satellite design. The thermal sub-system has the objective to regulate all satellite components with permitted temperature limits. The temperature limits of all satellite sub-systems need to be accepted so that satellite operational missions can be obtained. This paper discusses the amount of heat that occurs in low orbit satellites designed. The method used is the energy balance system that occurs in the main structure of the satellite (MPS, the main part of the satellite) using an energy balance equation. From the method used obtained from the initial thermal design, the maximum and minimum temperatures that occur in the main structure of the satellite (MPS) are $22.82^{\circ} \mathrm{C}$ and $-69.86^{\circ} \mathrm{C}$.
\end{abstract}

Keywords: Thermal, satellite, temperature, energy.

\section{PENDAHULUAN}

Satelit merupakan wahana benda yang bergerak dan mengorbit pada Bumi. Satelit dengan ukuran besar maupun kecil terdiri dari berbagai sub sistem yang masing-masing mempunyai fungsi dan peranan dalam menjalankan tugas-tugasnya sehingga operasional satelit dapat berjalan sesuai dengan misinya. Salah satu sub sistem satelit yang mengatur kebutuhan distribusi temperatur adalah sub sistem termal. Sub sistem termal sebagai sub sistem dasar satelit bertujuan menjaga semua komponen satelit [1] dengan batasan-batasan temperatur selama mode operasi satelit ketika tidak terlindungi dari lingkungan panas (termal) sinar kosmik antariksa. Biasanya keberadaan konveksi atmosfer di antariksa, seluruh kendali termal pada satelit diorbitnya dicapai dengan keseimbangan antara energi yang dipancarkan oleh satelit sebagai radiasi inframerah terhadap energi yang dihamburkan oleh komponen electric internal ditambah energi yang diserap dari lingkungan antariksa [2] seperti yang diperlihatkan pada GAMBAR 1. 


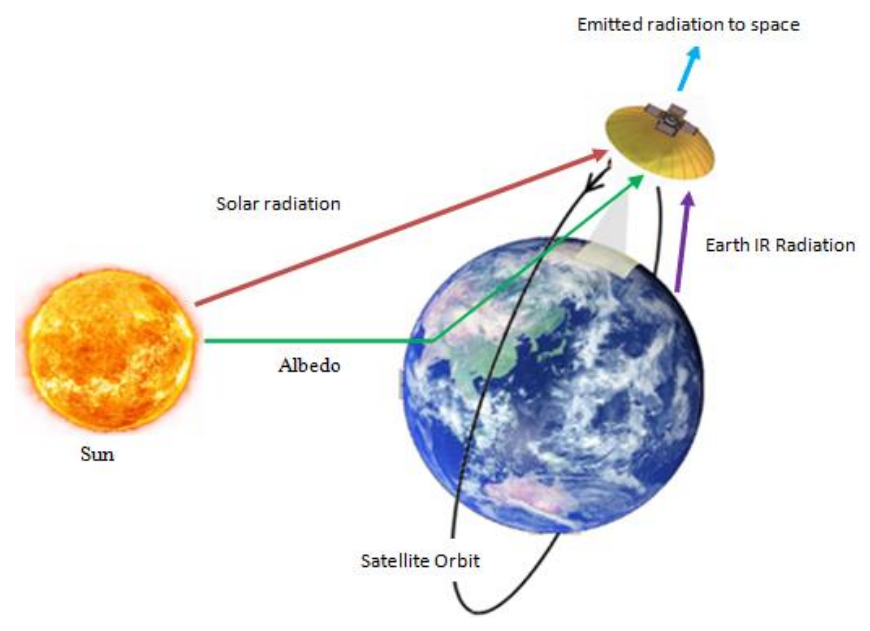

GAMBAR 1. Lingkungan termal satelit di space [2].

Satelit yang didesain dalam studi kajian ini adalah satelit dengan solar panel membentang yang mempunyai orbit rendah dan ketinggian orbit sekitar $600 \mathrm{~km}$ yang mengacu pada [3]. Keseimbangan termal dapat dicapai dengan adanya panas yang diterima oleh satelit dan panas yang dibuang ke space. Secara teoritis, persamaan matematis besarnya suhu yang terjadi pada satelit dapat diketahui dengan menggunakan persamaan 1 berikut:

$$
\underbrace{Q_{s u n}+Q_{e a}+Q_{a l}}_{\text {absorbed }}+\underbrace{Q_{W}}_{\begin{array}{c}
\text { internally } \\
\text { generated }
\end{array}}=\underbrace{Q_{p s}+Q_{p b}}_{\text {emitted }}+\underbrace{Q_{R 12}+Q_{C 12}}_{\text {converted }}
$$

Dimana, $Q_{S u n}=\alpha_{t} \cdot G_{S} \cdot A_{t} \cdot \operatorname{Cos} \theta ; Q e a=\varepsilon_{t} \cdot q I$ EIR.A.A. $\cdot F e ; Q_{A l b e d o}=-\alpha_{b} \cdot G_{S} \cdot A_{b} . K a \cdot F e \cdot \operatorname{Cos} \theta ; Q_{p s}=-\varepsilon_{t} \cdot \sigma \cdot A_{t} \cdot T^{4}$

$$
Q_{p b}=-\varepsilon_{b} \cdot \sigma \cdot A_{b} \cdot T^{4} ; Q_{R 12}=-\varepsilon_{1} \cdot \varepsilon_{2} \cdot F_{12} \cdot A \cdot \sigma \cdot\left(T_{1}^{4}-T_{2}^{4}\right) ; \text { dan } Q_{C 12}=-C_{12} \cdot\left(T_{3}-T_{4}\right)
$$

Dimana panas yang masuk adalah energi panas yang diserap oleh satelit yang terdiri dari panas sinar matahari $Q_{\text {sun, }}$ panas infrared bumi yang diserap $Q_{\text {ea }}$ dan panas albedo (energi yang dipantulkan dari bumi) $\mathrm{Q}_{\mathrm{al}}$ [2][4], ditambah panas yang dihasilkan oleh internal satelit $\mathrm{Q}_{\mathrm{w}}$. Sedangkan panas yang keluar adalah energi panas yang dipancarkan $\mathrm{Q}_{\mathrm{emitted}}$ yaitu $\mathrm{Q}_{\mathrm{ps}}$ dan $\mathrm{Q}_{\mathrm{pb}}$ dan energi (radiation into deep space) yaitu, $\mathrm{Q}_{\mathrm{R} 12}$ dan panas yang ditansmisikan, $\mathrm{Q}_{\mathrm{C} 12}$.

Banyak para engineer dan peneliti yang telah melakukan analisa sub sistem termal. Dari hasil analisa sistem termal satelit yang mereka lakukan, memberikan kita pengetahuan dan menambah banyak pengalaman tentang termal satelit, diantaranya Ueno K dkk yang melaporkan tentang sistem kontrol termal aktif radiator deploy satelit mikro dengan sistem HSP (heat storage panel) dan mLHP (micro loop heat pipe) dimana desain dasar dan analisa termalnya menggunakan model matematika [5]. Abolfazl Shirazi dan Mehran Mirshams, yang melakukan desain perangkat lunak STMS (Satellite Thermal Modeling Software) dengan menggunakan MATLAB GUI sebagai model analisa gradien suhu termal satelit [6]. DP. Michao dkk yang melakukan desain awal termal satelit dengan menentukan kombinasi dari optical properties yang digunakan pada permukaan panel surya dan memverifikasi hasil analisanya dengan menggunakan perangkat lunak Thermal Desktop dan SINDA/FLUINT [7]. Murat Bulut dkk yang melaporkan desain analisa kontrol termal pasif satelit CubeSat menggunakan ThermXL sebagai tools analisa termal untuk menghitung distribusi temperatur dan panas yang dibuang ke antariksa (heat rejection) [8]. Tobias Flecht yang telah 
mempelajari model satelit dengan menggunakan node berupa konduksi dan radiasi pada lingkungan antariksa, dimana simulasi pemodelan ini dilakukan dengan menggunakan perangkat lunak SYSTEMA/THERMICA [9]. Silva D.F dkk yang telah melakukan desain dan analisa sistem kontrol termal pasif pada satelit Amazonia-1 menggunakan SINDA/FLUINT sebagai thermal analyzer-nya dan verifikasi juga dilakukan dengan pendekatan analisa termal secara matematis [10].

\section{METODOLOGI}

GAMBAR 2 adalah gambar struktur satelit dengan solar panel yang membentang (DSP, Deployable Solar Panel), dengan didukung data termal optical properties dan juga data parameter lingkungan termal yang diberikan pada TABEL 1 dan digunakan dalam analisa suhu pada makalah ini. Tujuan utama dari menggunakan DSP pada satelit adalah untuk menambah luas penampang solar panel yang menghadap matahari ketika satelit di orbit agar dihasilkan jumlah daya yang lebih besar dibandingkan dengan satelit tanpa DSP [11].

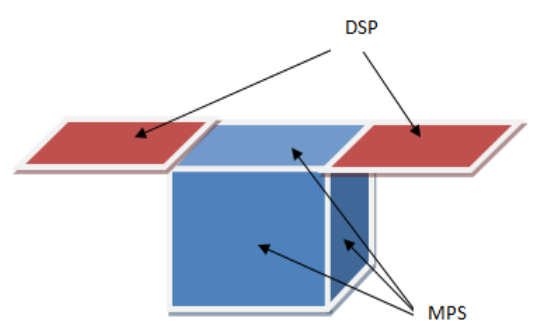

GAMBAR 2. Satelit dengan solar panel membentang (DSP)

TABEL 1. Parameter lingkungan termal yang digunakan

\begin{tabular}{|c|c|c|}
\hline Parameter & Maksimum & Minimum \\
\hline Solar flux (Gs) & \multicolumn{2}{|c|}{$1353 \mathrm{~W} / \mathrm{m}^{2} ;$ Average } \\
\hline Earth IR radiation, qEIR & \multicolumn{2}{|c|}{$237 \mathrm{~W} / \mathrm{m}^{2} ;$ Average } \\
\hline Power internal, Qw & $90 \mathrm{~W}$ & $0 \mathrm{~W}$ \\
\hline Albedo, a & & \\
\hline
\end{tabular}

Material dari MPS menggunakan solid aluminium, yaitu 7 buah pelat aluminium paduan 7075 T651 dengan ketebalan $10 \mathrm{~mm}$ yang terkoneksi satu dengan lainnya menggunakan baut. Aluminium pelat solid 7075 T651 dipilih karena kuat dan memiliki daya hantar panas yang baik sehingga panas pada sebuah pelat MPS dapat terdistribusi ke pelat MPS lainnya. Thermal properties aluminium paduan 7075 T651 dapat dilihat pada TABEL 2. Dalam desain awal, pada MPS dilakukan proses black paint (black anodize). Pada permukaan black paint memiliki nilai absorptivity $(\alpha)$ sebesar 0.67 dan emissivity $(\varepsilon)$ sebesar 0.89 sehingga ratio $\alpha / \varepsilon$ adalah 0.753 [12]. Satelit membawa subsistem high power amplifier dengan daya sebesar 1.500 Watt dan efisiensi sebesar $60 \%$, sehingga nilai maksimal power dissipation $\left(\mathrm{Q}_{W}\right.$ max. $)$ yang dibutuhkan sebesar 90 Watt, sedangkan nilai minimal power dissipation $\left(\mathrm{Q}_{\text {W min. }}\right)$ sebesar 0 Watt.

TABEL 2. Thermal properties Aluminium paduan 7075 T651

\begin{tabular}{lcc}
\hline \multicolumn{1}{c}{ Item } & Nilai & Unit \\
\hline Density & 2.810 & $\mathrm{~kg} / \mathrm{m}^{3}$ \\
Thermal Conductivity & 130 & $\mathrm{~W} / \mathrm{m}-\mathrm{K}$ \\
Specific Heat Capacity & 960 & $\mathrm{~J} / \mathrm{kg}-\mathrm{K}$ \\
\hline (Sumber: http://www.matweb.com/search/DataSheet.aspx?MatGUID=4f19a42be94546b686bbf43f79c51b7d\&ckck=1)
\end{tabular}

Persamaan 1 diatas untuk MPS satelit memperhatikan besarnya radiasi matahari, radiasi bumi, dan daya internal satelit untuk dilakukan analisa dalam menghitung besarnya suhu panas maksimum 
dan suhu dingin minimum. Adapun diagram alir perhitungan suhu yang digunakan dalam analisa perhitungan ini seperti yang diberikan pada GAMBAR 3 .

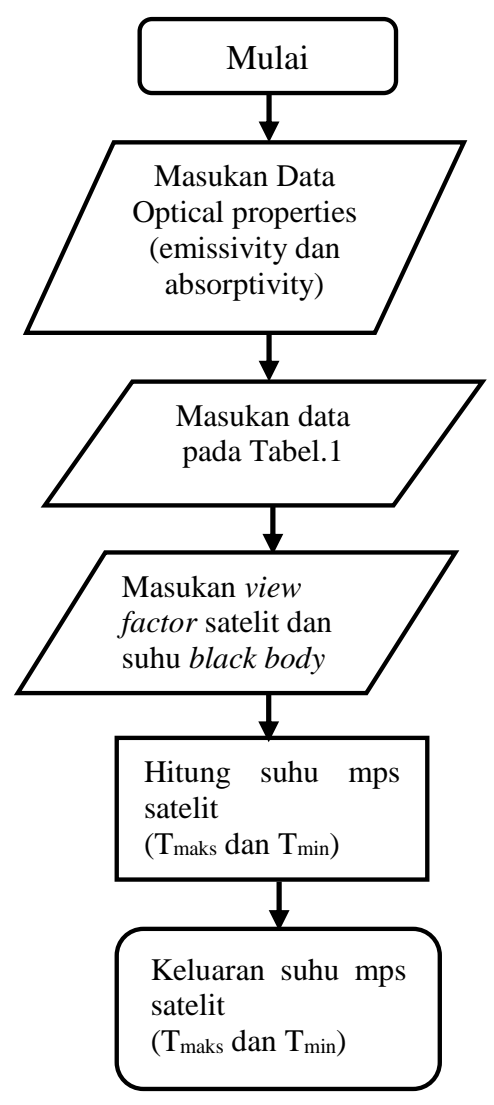

GAMBAR 3. Diagram alir perhitungan suhu

\section{HASIL DAN PEMBAHASAN}

\section{Sistem Kontrol Thermal}

Sistem kontrol termal yang bertugas untuk menjaga kestabilan suhu pada sistem komponen dan subsistem satelit sesuai dengan batasan suhu operasionalnya. Sistem kontrol termal (Thermal Control System) terdiri dari sistem termal aktif seperti penggunaan heater pada baterai, dan sistem termal pasif (seperti penggunaan radiator, termal paint pada permukaan struktur satelit, MLI (multi layer insulation), dan lain-lain. Biasanya satelit berukuran kecil seperti satelit nano, mikro dan piko yang berorbit rendah mengalami siklus termal yang tinggi pada daerah yang terkena sinar matahari langsung sehingga membutuhkan sistem termal pasif. Tingginya degradasi suhu yang terjadi pada satelit tipe orbit rendah ini memerlukan kontrol termal khusus agar batasan operasional suhu masingmasing komponen satelit dapat dijaga. Hal ini menjadi penting karena komponen yang digunakan berbasis industri mempunyai rentang range suhu antara $-40^{\circ} \mathrm{C}$ sampai $+80^{\circ} \mathrm{C}$ yang berbasis COTS (commercial off the self) dan sangat rentan dengan suhu luar. Pada makalah ini pembahasan analisa termal pada satelit mikro orbit rendah yang mempunyai ukuran seperti pada Tabel.3 dibawah ini. Data pada Tabel.3 serta data pendukung lainnya diperlukan untuk menghitung besarnya suhu panas maksimum dan suhu dingin minimum satelit. 
TABEL 3. Data satelit

\begin{tabular}{llc}
\hline \multicolumn{1}{c}{ Parameter } & \multicolumn{1}{c}{ Value } & Keterangan \\
\hline Orbit & $600 \mathrm{~km}$ & [3] \\
Dimensi Satelit & Length: $650 \mathrm{~mm} ;$ width: $650 \mathrm{~mm} ;$ height: 280 & \\
& mm & \\
\hline
\end{tabular}

\section{Sistem Thermal Satelit Deployment}

Dari persamaan 1 diatas, masing-masing energi dapat dijabarkan sebagai berikut: pada sisi masukan terdapat energi atau panas matahari yang diserap dari matahari di atas permukaan solar deployment $\left(\mathrm{Q}_{\mathrm{sun}}\right)$; panas earth $\mathrm{IR}$ bumi $\left(\mathrm{Q}_{\mathrm{ea}}\right)$; dan panas matahari yang dipantulkan dari bumi $\left(\mathrm{Q}_{\text {albedo }}\right)$; ditambah energi internal $\mathrm{Q}_{\mathrm{w}}$. Sedangkan pada sisi keluaran lainnya adalah radiasi pada dua permukaan (heat from solar deployment to inside main satellite body structure, $\mathrm{Q}_{\mathrm{R} 12}$ ); dan panas yang ditansmisikan oleh konduksi antara bagian depan dan bagian belakang solar deployment, $\mathrm{Q}_{\mathrm{C} 12}$.

Pada persamaan 1 diatas $\mathrm{Q}_{\text {sun, }} \mathrm{Q}_{\mathrm{ea}}$ dan $\mathrm{Q}_{\mathrm{al}}$ adalah panas yang terjadi pada MPS satelit. Tiga persamaan ini merupakan persamaan yang digunakan dalam menganalisa struktur utama satelit (MPS). Pada makalah ini hanya dibatasi dilakukan analisa besarnya suhu panas maksimum dan suhu dingin minimum yang terjadi pada struktur utama satelit (MPS) ditambah panas internal satelit Qw. Sehingga dari ketiga sumber panas tersebut (panas matahari yang diserap dari matahari di atas permukaan solar deployment $\left(\mathrm{Q}_{\text {sun }}\right)$; panas earth IR bumi $\left(\mathrm{Q}_{\mathrm{ea}}\right)$; dan panas matahari yang dipantulkan dari bumi $\left(\mathrm{Q}_{\text {albedo }}\right)$; ditambah energi internal $\mathrm{Q}_{\mathrm{w}}$, maka kita dapatkan persamaan matematis dan dapat kita ketahui besarnya suhu panas maksimum dan suhu dingin minimum yang terjadi pada MPS satelit, seperti yang diberikan pada persamaan 2 [13] berikut;

$$
\begin{gathered}
A_{\text {solar }} \cdot q_{S}+F \cdot A_{\text {surface }} \cdot \sigma \cdot T_{E}{ }^{4}+F \cdot A_{\text {surface }} \cdot a \cdot q_{S}+Q=A_{\text {surface }} \cdot \sigma \cdot T^{4} \\
T=\sqrt[4]{\frac{q_{S}}{4 \pi}\left(\frac{1}{4}+F \cdot a\right)+F \cdot T_{E}{ }^{4}+\left(\frac{Q}{A_{\text {surface }} \cdot \sigma}\right)}
\end{gathered}
$$

Dimana $F$ adalah faktor sudut pandang antara bumi dan satelit, $T_{E}$ adalah suhu rata-rata blackbody bumi sebesar $255^{\circ} \mathrm{K}$ [14], $\sigma$ adalah konstanta Stefan Boltzmann, dan Q adalah panas internal satelit. Sehingga dengan menggunakan data yang diberikan pada TABEL 1 dan dengan menggunakan rumus persamaan matematis yang diberikan pada persamaan 2 jika panas internal satelit diabaikan, maka didapatkan hasil besarnya suhu panas maksimum dan suhu dingin minimum yang terjadi pada MPS satelit yaitu sebesar $22.82^{\circ} \mathrm{C}$ dan $-69.86^{\circ} \mathrm{C}$, dari suhu tersebut dapat dikatakan bahwa batasan suhu yang terjadi pada MPS satelit dapat menjaga batasan suhu operasional komponen satelit yang diijinkan.

\section{SIMPULAN}

Sub sistem termal merupakan manajemen sub sistem engineering satelit yang menjaga semua suhu yang terjadi pada sub sistem satelit lainnya, agar satelit dapat terlindungi dari radiasi suhu ekstrim angkasa dan dapat mengganggu kerja operasi satelit di orbit, dan dengan menggunakan rumus matematis dapat kita ketahui besarnya suhu panas maksimum dan suhu dingin minimum yang terjadi pada satelit. Sehingga dengan analisa ini diharapkan dapat menjadi acuan dalam mendesain sistem satelit, dengan di dukung data yang dibutuhkan. Dari analisa yang dilakukan dengan pendekatan matematis diketahui besarnya suhu panas maksimum dan suhu dingin minimum MPS satelit yaitu sebesar $22.82^{\circ} \mathrm{C}$ dan $-69.86^{\circ} \mathrm{C}$, dapat melindungi dan menjaga komponen satelit dari suhu ekstrim antariksa. 


\section{REFERENSI}

[1] L. Celotti, M. Solyga, and B. Cefalo, "PEASSS thermal subsystem: challenges in the thermal design of CubeSat missions", Proceedings of $45^{\text {th }}$ International Conference on Environmental Systems, Bellevue, Washington, 2015, Paper No. ICES-2015-34.

[2] Spacecarft Thermal Control Handbook: Fundamental Technologies. El Segundo: The Aerospace Press. Gilmore D.G, 2002.

[3] Pusteksat-LAPAN dan CEReS Chiba University Team, PDR LAPAN Chiba / A5 Satellite, 2017.

[4] Fortescue P, Stark J, Swinerd G, Editors. Spacecraft System Engineering. $3^{\text {rd }}$ Ed, Chichester: John Wiley \& Sons, 2003.

[5] A. Ueno, K. Yamada, and H. Nagano, "Study on Functional Thermal Control Systems for High-Power Micro Satellite", in Proceedings of $47^{\text {th }}$ International Conference on Environmental Systems, Charleston, South Carolina, 2017, Paper No. ICES-2017-366.

[6] A. Shirazi and M. Mirshams, "Software Development for Satellite Thermal Design," in Applied Mechanics and Materials, Vol. 390, 2013, pp 703-707.

[7] D. P. Mitchao, T. Totani, M. Wakita, and H. Nagata, "Preliminary Thermal Design for Microsatellites Deployed from International Space Station's Kibo Module", in Journal of Thermophysics and Heat Transfer, Vol. 32, No.3, 2018, pp. 789-798.

[8] M. Bulut, A. Kahriman and N. Sozbir, "Design and Analysis for Thermal Control System of Nanosatellite", in ASME 2010 International Mechanical Engineering Congress and Exposition, Vol.10, 2010, No. IMECE2010-39716, pp. 863-866.

[9] T. Flecht, "Thermal modelling of the PICSAT nanosatellite platform and synergetic prestudies of the CIRCUS nanosatellite", Master's Thesis. Lulea University of Technology, Department of Computer Science, Electrical and Space Engineering, 2016.

[10] Silva D.F., Muraoka I., and Garcia E.C, "Thermal Control Design Conception of the Amazonia-1 Satellite," in Journal Aerospace Technology Management, Vol.6, No.2, 2014, pp.169-176.

[11] T.K. Das, T. Totani, M. Wakita, and H. Nagata, "Thermal Analysis of Nano and Micro Satellite Pointing to The Earth with Deployable Solar Panel on Sun-Synchronous Orbit by Small Number of Nodes," in Mechanical Engineering Research Journal, Vol.99, 2013, pp. 79-85.

[12] D. P. Mitchao, T. Totani, M. Wakita, H. Nagata, and Yuji Sakamoto, "Thermal Design and on-Orbit Validation of the First Philippine Micro-Satellite: DIWATA-1", in 47th International Conference on Environmental Systems, Charleston, South Carolina, 2017, Paper No. ICES-2017-130.

[13] D. Q. Dinh, Thermal Modeling of NanoSat, California: San Jose State University, San Jose, 2008.

[14] C. B. VanOutryve, A Thermal Analysis and Design Tool for Small Spacecraft, California: San Jose State University, San Jose, 2008. 